\title{
Modelling the fate of gaseous radionuclides in crops
}

\author{
C.D. Collins and G. Shaw \\ Department of Environmental Science and Technology, Imperial College of Science \\ Technology and Medicine, Prince Consort Road, London SW7 2BP, U.K.
}

\begin{abstract}
Abatract. Models to predict the fate of gaseous radionuclides hove received considerable attention in the literature. They vary considerably in their complexity from simple models wilh litle attempl to reflect processes within the system to those with a high level of mechanistic complexity. The following paper describes an approach that is a compromise between simplicity and realism. In the proposed model deposition is trealed traditionally as the multiple of the air concentration, deposition velocity and exposure time but the subsequent allocation of radioactivity to different plant parts is determined by the growth rote of individual plant components relative to the total growth rate of the plant. The construction of the model is described along with its validation against independent data sets for the allocation of ${ }^{35} S$ and ${ }^{14} \mathrm{C}$ in cabbage and bean following deposition in the form of $\mathrm{CO}^{35} \mathrm{~S}$ and ${ }^{14} \mathrm{CO}_{2}$ at a number of discrete points in the growth season.
\end{abstract}

\section{INTRODUCTION}

Predictive models for the fate of radionuclides in the environment have been developed since the beginnings of radioecology, which coincided with the birth of the nuclear programme. There are a number of models which have the potential to predict the concentration of radionuclides in crops following releases of gaseous radionuclides to the atmosphere, such as SPADE, SULPHUR, CARBON2 and UFOTRI [1] [2] [3] [4], although these vary widely in complexity. For example, CARBON2 and SULPHUR are simple compartment models with rate constants defining transfers between compartments. On the other hand, UFOTRl, which models the behaviour of tritium in the environment, is a more complex model that addresses the underlying plant physiological processes such as evapotranspiration. From our research at Imperial College over a number of years we have observed that the major sinks for radionuclides following deposition to plant surfaces are those plant components growing or developing after the deposition event. This has been observed for a number of gaseous radionuclide species such as ${ }^{3} \mathrm{HTO}, \mathrm{CO}^{33} \mathrm{~S}, \mathrm{H}_{2}{ }^{35} \mathrm{~S},{ }^{14} \mathrm{CO}_{2}$ and ${ }^{125} \mathrm{CH}_{3} \mathrm{I}$ [5], [6], [7] [8], [9] and [10]. We therefore decided to construct a simple model which would simulate the allocation of radionuclides to plant components based on the growth rate of individual crop components in order to investigate if this relatively simple approach could provide good predictions of the crop activity concentrations of radionuclides following deposition.

\section{MODEL CONSTRUCTION}

The inputs into the model are the deposition velocity, which derived from a number of literature sources [11], [12], [13], [14], the exposure time and air concentration which are dependent on the release event. The multiple of these factors is then multiplied by the biomass of the crop, which provides the total activity inventory for the crop immediately following deposition. The plant biomass is provided by a single Richards function for the growth of each major LK crop. These functions were obtained from growth data in the literature which were then fitted, using a least square fitting method, to the available experimental data. In the case of cabbage described here, four data sets were used [8], [15], [16], [17]. These biomass data sets are held in libraries within the model (Figure 1.). Following the calculation of total deposition, the allocation of a radionuclide to individual crop components is determined by a leaf export rate multiplied by the individual growth rate of the component relative to the total growth rate of the crop. Crop growth rates are determined using the differentiated form of the fitted Richards function, described earlier. The export rate from the leaves was determined by an independent experiment in the case of ${ }^{35} \mathrm{~S}$, 
in which single leaves of mature bean plants were exposed to ${ }^{35} \mathrm{~S}$ and the subsequent export of this radionuclide determined over a time course of three weeks. In the case of ${ }^{14} \mathrm{C}$, literature values determined for bean plants were used [18]. The activity concentration in the edible crop component is then calculated from the weight of the edible portion on the day of interest, provided by the Richards function, and the amount of activity as discussed. The model was coded using Model Maker software (Cherwell Scientific, U.K.). A schematic diagram of the model is provided in Figure 1.

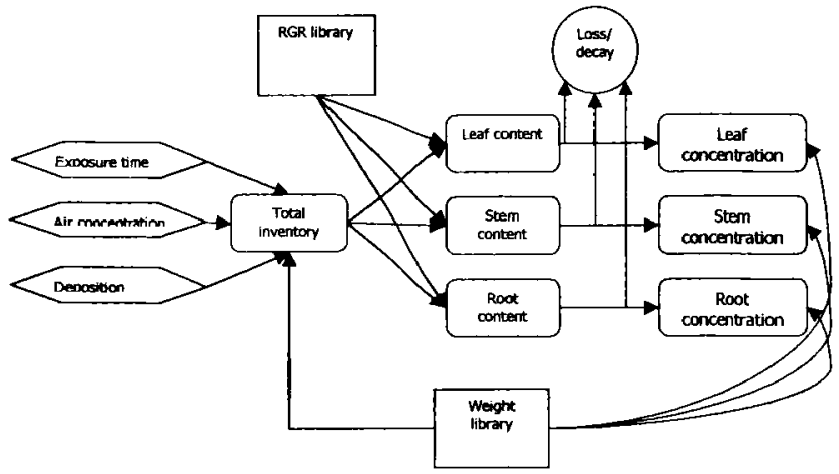

Figure 1: Schematic diagram showing the structure of the model.

Independent data sets were used to validate the model. The data sets were obtained from a number of exposures of whole crops of cabbage and bean to ${ }^{14} \mathrm{CO}_{2}$ and $\mathrm{CO}^{35} \mathrm{~S}$ over the crops' entire growth cycles [6], [7].

\section{RESULTS}

Initial simulations using the model for a cabbage crop exposed to ${ }^{14} \mathrm{CO}_{2}$ at early and middle season in the growth cycle under-predicted the total ${ }^{14} \mathrm{C}$ deposition to the crop (Figure 2). This was largely a result of the default $V_{g}$ in the model being lower than that calculated from the experiment (Table 1). However, the model provided an accurate simulation of the declining ${ }^{14} \mathrm{C}$ activity in the leaf, stem and root material, although it under-predicted ${ }^{14} \mathrm{C}$ allocation to the stem and root compartments at both the exposure dates.

Table 1:Comaprison of model and experimental mass normalised deposition velocities $\left(\mathrm{V}_{\mathrm{z}}\right)$.

\begin{tabular}{|l|c|c|}
\hline \multicolumn{1}{|c|}{ Exposure } & $\begin{array}{c}\mathrm{V}_{\mathbf{g}} \text { model } \\
\left(\mathrm{cm}^{3} \mathbf{g}^{-1} \mathbf{s}^{-1}\right)\end{array}$ & $\begin{array}{c}\mathbf{V}_{\mathbf{g}} \text { experimental } \\
\left(\mathrm{cm}^{3} \mathbf{g}^{-1} \mathbf{s}^{-1}\right)\end{array}$ \\
\hline${ }^{14} \mathrm{CO}_{2}$ cabbage early season & 0.3 & 0.39 \\
\hline $\mathrm{CO}_{2}$ cabbage middle season & 0.3 & 0.49 \\
\hline $\mathrm{CO}^{35} \mathrm{~S}$ cabbage early season & 0.6 & 1.22 \\
\hline $\mathrm{CO}^{35} \mathrm{~S}$ cabbage middle season & 0.6 & 4.80 \\
\hline $\mathrm{CO}^{35} \mathrm{~S}$ bean early season & 0.6 & 3.21 \\
\hline $\mathrm{CO}^{35} \mathrm{~S}$ bean middle season & 0.6 & 2.18 \\
\hline
\end{tabular}




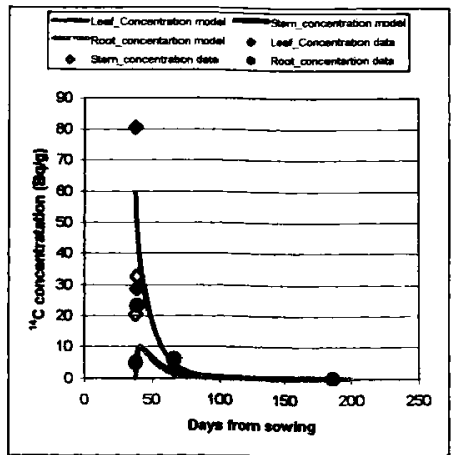

(a)

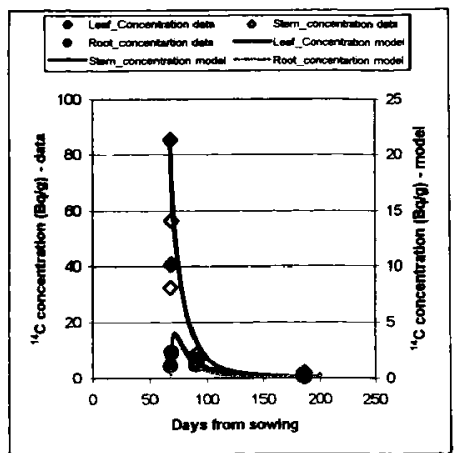

(b)

Figure 2: Comaprison of model and cxperimental data for cabbagc exposed to ${ }^{14} \mathrm{CO}_{2}$ at (a) carly season and (b) middle season.

The principal results of a model simulation of ${ }^{35} \mathrm{~S}$ distribution in a cabbage crop exposed to $\mathrm{CO}^{35} \mathrm{~S}$ were similar to those for ${ }^{14} \mathrm{CO}_{2}$ (Figure 3). Once again, a lower total initial deposition resulted from a lower default $\mathrm{V}_{\mathrm{B}}$ entered into the model than that calculated from the experimental data (Table 1). As for the ${ }^{14} \mathrm{CO}_{2}$ simulation, the decline in ${ }^{35} \mathrm{~S}$ activity concentration in plant compartments following initial contamination, as a result of the processes of radioactive decay and growth dilution, was predicted well. Furthermore, allocation of ${ }^{35} \mathrm{~S}$ to the stem and the root appeared to be better simulated for ${ }^{35} \mathrm{~S}$ than in the case of ${ }^{14} \mathrm{C}$

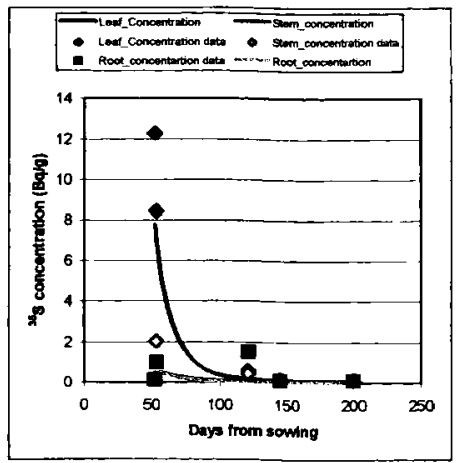

(a)

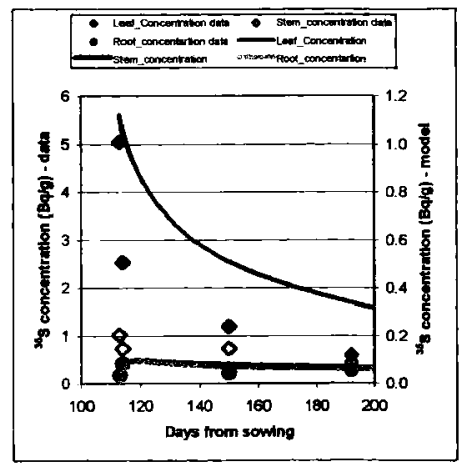

(b)

Figure 3:Comaprison of model and experimental data for cabbage exposed to $\mathrm{Co}^{35} \mathrm{~S}$ at (a) early season and (b) middle season. 
The model was then validated against the independent bean data set (Figure 4). A bean crop is more complex than cabbage since it develops reproductive structures in the form of beans and pods (combined in this example) so should provide a more thorough test of the applicability of the model. Once again, there was an under-prediction of the total initial deposition and a reasonably accurate prediction of the declining activity concentration in individual plant parts. Most marked in this case was the low degree of allocation to crop components. The simulated export of ${ }^{35} \mathrm{~S}$ from the leaf is clearly too slow despite the rates being determined in an experiment using bean plants. It is also notable that, following rapid leaf growth in the early season, the model under-estimates final harvest leaf activity concentration of ${ }^{35} \mathrm{~S}$ while over-estimating it for the later season exposures when growth is less rapid.

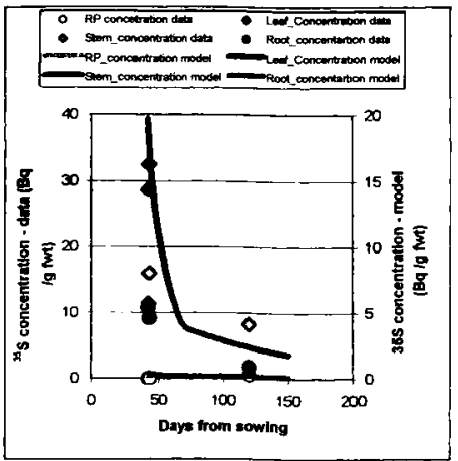

(a)

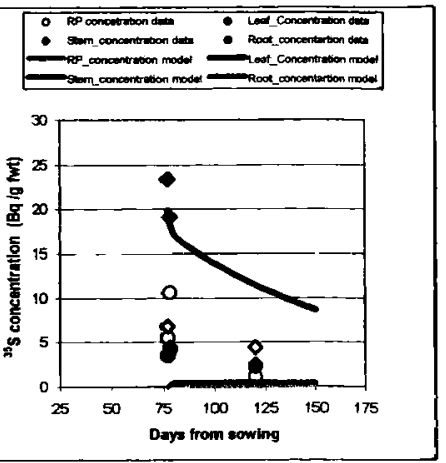

(b)

Fipare 4:Comaprison of model and experimental data for bean exposed to $\mathrm{CO}^{35} \mathrm{~S}$ at (a) earty season and (b) middle season

When the export constant was increased the agreement of the model with the experimental data was considerably improved (Figure 5), although the predicted allocation of ${ }^{35} \mathrm{~S}$ to the reproductive parts was considerably lower than the data. This is thought to result from the higher ratio of dry weight to fresh weight of reproductive parts compared with other crop components (reproductive parts c. 0.4 , other components c 0.1 ). If plant fresh weights are used for growth rates libraries in the model, which subsequently determine allocation, an under-prediction of carbon and sulphur allocation would be expected as a consequence of the higher water content of non reproductive components.

\section{DISCUSSION}

The use of plant growth rates to determine the distribution of gaseous radionuclides within crops, following deposition from the atmosphere, appears to be reasonably robust. In its current configuration the model under-predicts the total initial deposition of radionuclides largely as a consequence of defautt $\mathrm{Vg}$ values, which are lower than those observed in experiments used for the model validation. It is not considered appropriate to change the model default $\mathrm{V}_{\mathrm{g}}$ values, however, as these have been derived from a number of studies, including field measurement campaigns. The experimental data used here were obtained from a controlled environment study in which conditions were ideal for plant assimilation of gaseous pollutants (i.e. high light, low canopy resistance, well-watered crops). The subsequent allocation and loss of radioactivity were simulated well by the model judging by the correlation coefficients obtained, which were $0.67,0.85$ and 0.83 for the prediction of ${ }^{14} \mathrm{C}$ concentrations in cabbage and ${ }^{35} \mathrm{~S}$ concentrations in cabbage and bean, respectively 


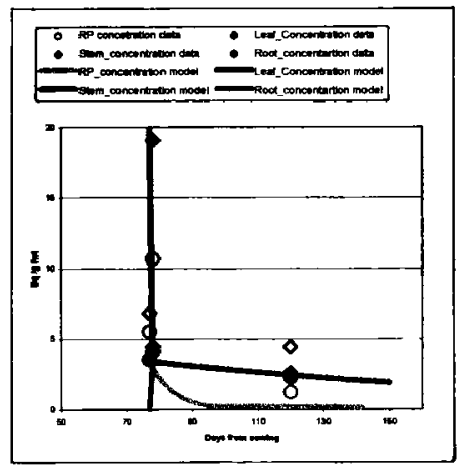

Figure 5:Comaprison of model and experimental data for bean exposed to $\mathrm{CO}^{35} \mathrm{~S}$ at middle season with enhanced export ratc.

The initial allocation to crop components appeared to be under-predicted by the model and further data are required to validate the current export parameters used since they are currently derived from only one experiment for each radionuclide. Interestingly, when the export rate was increased for the middle season exposure of bean to $\mathrm{CO}^{35} \mathrm{~S}$ the model appeared to simulate the data more reliably (c.f. Figure 4 and 5 ). However, the correlation coefficient for this model simulation declined for the model run concerned from 0.85 to 0.77 when the export rate was altered.

In conclusion it can be stated that this growth rate-based modelling approach shows promise and, once data for growth curves are collected, it can easily be adapted to a variety of crops. Future modelling efforts will be concentrated on iodine radioisotopes and tritiated water vapour following gaseous deposition.

\section{Acknowledgments}

The authors are grateful to BNFL, British Energy and the UK Food Standards Agency for their support over recent years.

\section{References}

1. Jackson, D. and P.J. Coughtrey, Specification of standardised radionuclide input scenarios, agricultural practices and results presentation for $S P A D E, .1985$, Associated Nuclear Services.

2. Pearce, K.I, S Nair, and C.D. Collins, SULPHUR - A computer code for the prediction of time dependent uptake of 35-S by crops, . 1991, Nuclear Electric.

3. Pearce, K.I., CARBON 2 - A computer code for the prediction of time dependent uptake of carbon14 by crops., 1992, Nuclear Electric, Technology Division.

4. Raskob, W., Description of the new version 4.0 of the tritium model UFOTRI including user guide, . 1993, Institut fur Neutronenpyhsik und Reaktorteknik, Kernforschungszentrum Karlsruhe: Karlsruhe. p. 92.

5. Brudenell, A. J.P., C.D. Collins, and G. Shaw, Dynamics of tritiated water (HTO) uptake and loss by crops after short term armospheric release. Joumal of Environmental Radioactivity, 1996. 36: p. 197-218. 
6. Collins, C. and J. Bell, Experimental Studies On the Deposition to Crops Of Radioactive Gases Released From Gas-Cooled Reactors .I. Carbonyl Sulfide-35. Journal Of Environmental Radioactivity, 1996.30(2): p. 99-115.

7. Collins, C.D. and J.N.B. Bell, Experimental studies on the deposition to crops of radioactive gases released from gas-cooled reactors - II. Hydrogen sulphide-35. Joumal of Environmental Radioactivity, 1997. 34(3): p. 237-251.

8. Tucker, S., Allocation of carbon-14 in UK crops, in Department of Science and Technology. 1997, Imperial College of Science Technology and Medicine: London.

9. Collins, C.D., A.E. Gravett, and J.N.B. Bell. The Deposition and Metabolism of Methyl /I25/Iodide by crops in ICRPA Conference. 1996.

10. Stewart, A., The deposition of gaseous $C-14, S-35$ and $H-3$ to fruit crops, in Department of Science and Technology. 2001, Imperial College of Science Technology and Medicine: London.

11. Taylor, G.E., et al., The flux of sulphur containing gases to vegetation. Atmospheric Environment, 1983. 17(4): p. 789-796.

12. Chadwick, R.C., Uptake of $\mathrm{H}_{2} \mathrm{~S}$ and $\mathrm{COS}$ by vegetation, 1977, A.E.R.E. Harwell: Harwell.

13. Brown, K.A., S.M. Kluczewski, and J.N.B. Bell, Metabolism of [S-35] carbonyl sulphide in perennial ryegrass (Lolium perenne L) and radish (Raphamus sativus $L$ ). Environmental and Experimental Botany, 1986. 26(4): p. 355-362

14. Kluczewski, S.M. et al, The uptake of 35S-carbonyl sulphide by plants and soils, in Ecological aspects of radiomuclide release, J.N.B.B.a.T.M.R. P. J. Coughtrey, Editor. 1983, Blackwell Scientific Publications: Special publications series of the British Ecological Society No.3. p. 91-104.

15. Salo, $T$., Effects of band placement and nitrogen rate on dry matter accumulation, yield and nitrogen uptake of cabbage, carrot and onion. Agricultural and Food Science in Finland, 1999. 8(2): p. $159-+$.

16. Lotz, L.A.P., et al., Yield losses of white cabbage caused by competition with clovers grown as cover crop. Netherlands Journal of Agricultural Science, 1997. 45(3): p. 393-405

17. Drew, D.H., Irrigation Studies on Summer Cabbage. Journal of Horticultural Science, 1966. 41: p. 103-114.

18. Ismail, A.M.A and G.A. Sagar, The influence of leaf age, leaf position and sinks on the rate of export and partition of ${ }^{14} \mathrm{C}$ at different stages of development following assimilation of ${ }^{14} \mathrm{CO}_{2}$ by a single leaf of Vicia faba, L. Joumal of Horticultural Science, 1981. 56: p. 55-63. 